\title{
Design implications for teamwork in ATC
}

\author{
Åsa Svensson ${ }^{1}\left[\right.$. Ulrika Ohlander ${ }^{2} \cdot$ Jonas Lundberg $^{1}$
}

Received: 26 November 2018 / Accepted: 20 June 2019 / Published online: 2 July 2019

(c) The Author(s) 2019

\begin{abstract}
In air traffic control (ATC), teamwork is a key component among air traffic control operators (ATCOs) to safely direct the aircraft through the sky and on the ground. To be able to design for future ATC systems, we must understand how ATCOs work together, their teamwork, and how they experience and perceive teamwork, in different ATC environments. We conducted interviews with 16 ATCOs working in four different ATC environments (en-route control, terminal area control, tower control for a small airport and tower control for a large airport in Sweden) and analysed the results in the light of the "Big Five" model of teamwork. The main contributions of this paper are to show: (1) how eight teamwork factors are differently manifested by the ATCOs in the different ATC environments, (2) that teamwork in ATC is important during routine operations, during stressful work, and during abnormal situations, and (3) that the design of the organisation, the environment, and the tools, affects teamwork and the importance of different teamwork factors.
\end{abstract}

Keywords Air traffic control $\cdot$ Teamwork $\cdot$ Design $\cdot$ En-route $\cdot$ TMA $\cdot$ Air traffic control tower

\section{Introduction}

Air traffic control operators (ATCOs) work closely together to deliver the service of safely directing aircraft through the sky and on the ground. ATCOs work solo, in pairs, or in groups, with responsibility for a specific part of the airspace, i.e. sectors or control zones, depending on the control environment. The ATCOs coordinate traffic between sectors, to make the route optimal and as smooth as possible for each aircraft, and for aircraft in the sectors around them, since traffic flows through several sectors. This requires teamwork between the ATCOs, the pilots, the ground service personnel and other stakeholders (such as airports, airlines, the military, etc.) to maintain an efficient and safe environment.

Teamwork has been extensively analysed in many domains, such as aviation (Wilson et al. 2010), medical care (Hall 2005; Leonard et al. 2004; Manser 2009), air traffic control (ATC) in terminal airspace (Gyles and Bearman 2017), ATC during abnormal situations (Malakis and Kontogiannis 2008; Malakis et al. 2010), global virtual teams

Åsa Svensson

asa.e.svensson@liu.se

1 Department of Media and Information Technology, Linköping University, Norrköping, Sweden

2 Saab Aeronautics, Linköping, Sweden
(Derven 2016), computer-supported collaborative learning (Kay et al. 2006a), and the performance of sport, such as football (Neville et al. 2016). Extensive research has been carried out regarding teamwork, effective teamwork, teamwork performance, and team cognition (Salas et al. 2008). However, few studies have focused on the subjective experience of ATCOs, or on their opinions regarding teamwork in different air traffic control environments in everyday operations. The fact that effective teamwork involves the ability of team members to communicate and share knowledge (Cooke et al. 2003, 2013) makes teamwork a complex phenomenon to study since it can manifest in many different ways depending on the context. In addition, unconditional trust between the team members is required to create synergy in the team (Jones and George 1998).

ATCOs carry out challenging and demanding tasks under time pressure. This requires effective teamwork in distributed environments (pilots, ground service personnel, other stakeholders, etc.). Current technological advances in digital communication and decision support can provide better support for such activities. Since traffic is increasing over time, the development of support tools in ATC is constantly ongoing to meet the higher demands from different stakeholders.

To successfully design ATC systems which meet these demands, but still maintain a high degree of safety, we need to investigate how the ATCOs are working in current 
systems and what kind of teamwork they have established among themselves. This is to design future ATC systems that both can meet the new demands, and still support the ATCOs in the way they work together. We have applied the "Big Five" model for effective teamwork (Salas et al. 2005) when investigating teamwork in four different ATC environments: ATC for en-route control, terminal area control, tower control at a small airport, and tower control at a large airport. We carried out interviews with 16 ATCOs, who contributed to a deeper understanding of how they explain and perceive teamwork, and which teamwork factors they consider to be the most important in their daily work.

The "Big Five" model proposed by Salas et al. (2005) suggests that eight factors are necessary for effective teamwork (five core factors and three coordinating mechanisms): team leadership, mutual performance monitoring, backup behaviour, adaptability, team orientation, shared mental models, mutual trust and closed-loop communication. The model uses these factors to describe the elements of teamwork (Kay et al. 2006a). In aviation, this model has previously been used to describe the teamwork between fighter pilots (Ohlander et al. 2016b).

The work carried out in air traffic control differs between tower control, terminal area control and en-route control, and it is important to acknowledge these differences. It is already known that differences regarding both individual work and teamwork are important in abnormal situations (Malakis and Kontogiannis 2008; Malakis et al. 2010). However, differences regarding individual work and teamwork during routine operations must also be considered when designing support for ATCOs. We cannot design one system that fits all environments, but rather a system that will support an operator, or several operators in a team, in a specific environment.

To be able to design for future ATC systems, the aim of this descriptive study is to understand how ATCOs work together, and how they experience and perceive teamwork in different ATC environments. The main contributions of this paper are to show: (1) how eight teamwork factors are differently manifested by the ATCOs in different ATC environments, (2) that teamwork in ATC is important during routine operations, during stressful work and during abnormal situations, and (3) that the design of the organisation, the environment, and the tools affect teamwork and the need for different teamwork factors. This knowledge will form a foundation for future research into how teamwork is perceived in different ATC environments, and it has design implications for how to build ATC systems that support the teamwork factors that ATCOs need most.

\section{Background}

This section presents an overview of the air traffic control environments included in this study, followed by a description of the "Big Five" model (Salas et al. 2005) of teamwork. This model uses five core factors: team leadership, mutual performance monitoring, backup behaviour, adaptability and team orientation, and three coordinating mechanisms: shared mental models, mutual trust, and closed-loop communication to analyse the teamwork. This study uses the "Big Five" model as the theoretical foundation to describe teamwork in ATC.

\subsection{Air traffic control}

ATC is a ground-based service provided by ATCOs, located in towers at airports or in control centres. The ATCO's main task is to direct aircraft on the ground and through controlled airspace, and to give advisory services to aircraft in non-controlled airspace. For ATC worldwide, the main purpose is to prevent collisions, organise the flow of the traffic and provide information and support for pilots. All ATCOs in Sweden undergo the same basic ATC education, after which they specialise towards a certain control environment. After they have graduated, they undergo safety and competence training every year to maintain their ATCO licence. In Sweden, there are, to simplify, three types of air traffic control environments: en-route control, terminal area control and tower control (Fig. 1).

We have studied all three ATC environments: en-route, terminal control area (TMA), and two different tower control environments (one for a small airport and one for a large airport), resulting in a total of four environments. The different environments are explained below.

En-route control is the service provided to aircraft flying between airports. The sky is divided into sectors for different ATCOs to control, and the responsibilities of the ATCOs depend on the flight procedures used. In Sweden, ATCOs normally work in pairs with one executive (E) and one planner $(\mathrm{P})$ around and within the same sector. $\mathrm{E}$ has responsibility for traffic management within the sector and for the tactical tasks, while $\mathrm{P}$ has responsibility for planning and coordination of the traffic entering the sector, existing within it, or exiting from it. Even though $\mathrm{E}$ and $\mathrm{P}$ work and sit closely together, they each have an individual workstation equipped with radar, a voice communication system, lists of information of aircraft, and so on. The work shift for en-route controllers is normally $20-60 \mathrm{~min}$ of work followed by a 20 -min break, which is repeated for approximately $8 \mathrm{~h}$ in total. 


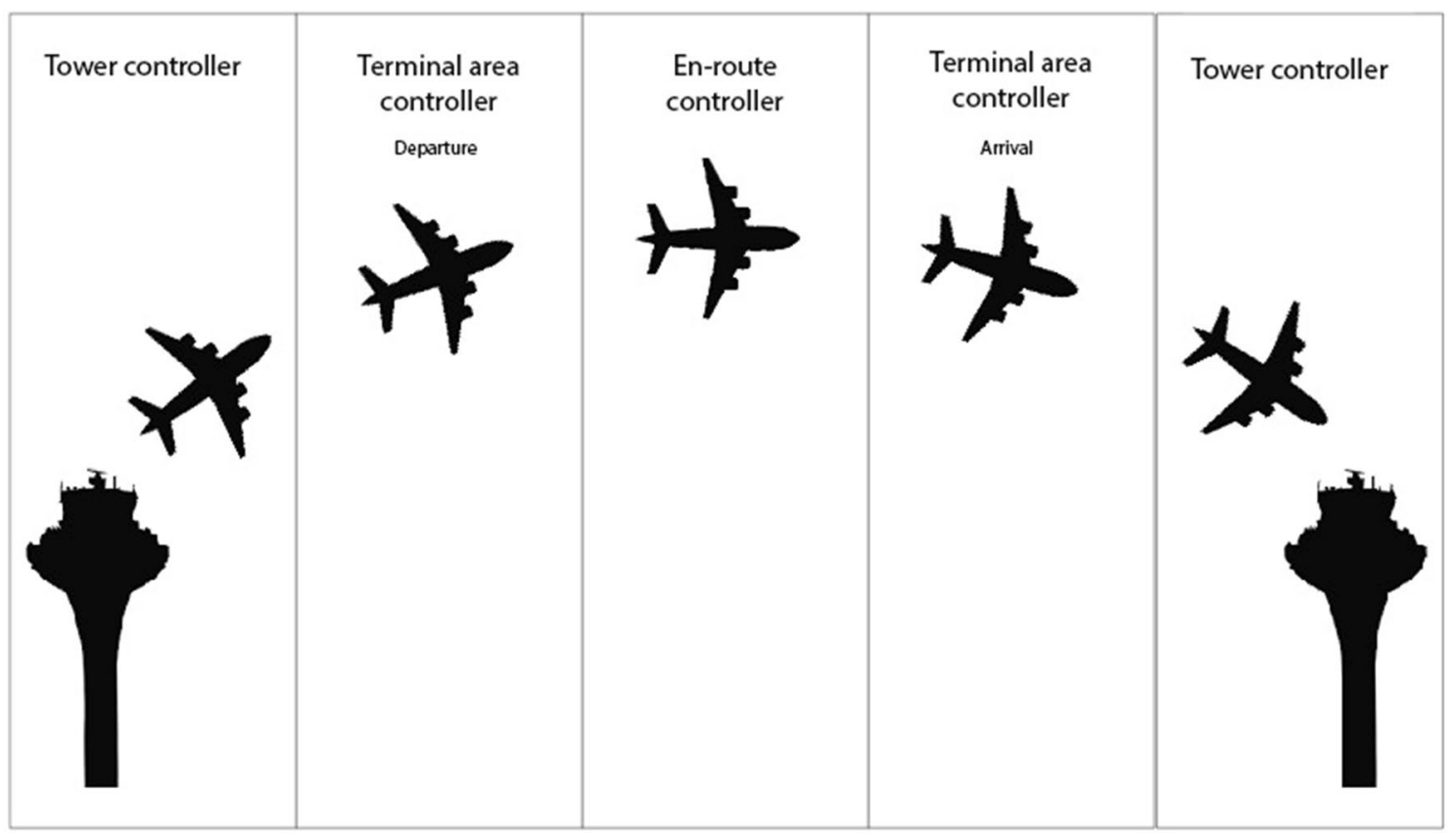

Fig. 1 Air traffic control environments in Sweden

A TMA is normally established in the vicinity of one or more major aerodromes. The main function of the terminal control is to guide the aircraft to the control zone (around the airport), on a specific heading, speed and altitude. In a TMA, the ATCOs work in groups of two to five people (depending on the amount of traffic to be handled). Each ATCO has an individual workstation close to the others, again equipped with radar, a voice communication system (which is used to communicate with the pilots, ATCOs in adjacent sectors and those operating other related services), lists of information of aircraft, etc. Communication between ATCOs is conducted either through the voice communication system, or face-to-face with ATCOs at neighbouring workstations. Each ATCO working in terminal control has an individual sector and does not work as closely with others as is the case in en-route control. The work shift for TMA controllers is normally 20-60 min of work followed by a 20-min break, which is repeated for approximately $8 \mathrm{~h}$ in total. The facility in which both terminal area control and en-route control take place is normally called an "air traffic control centre".

The definition by the International Civil Aviation Organization (2005) of the work of a tower controller is to prevent collisions between aircraft on the manoeuvring area and to prevent collisions between aircraft and obstructions. (The manoeuvring area is the section of the airport used for takeoff, landing and taxiing, excluding aprons). Moreover, the task of ATCOs is to promote an expeditious flow of traffic. These tasks depend on visual observation, and the procedures used change when visibility conditions change.
ATCOs can either work solo, together with an air traffic control assistant or with other ATCOs, depending on the quantity of traffic (which depends, of course, on the size of the airport). The airport for the small airport tower used in this study had approximately 30,000 movements (arrivals and departures) in 2017. An ATCO in this tower works together with an air traffic control assistant, who handles ground vehicles. The ATCO and the air traffic control assistant have one set of ATC tools and functions, including, for example, a radar screen, a flight-strip progress-board, and a voice communication system. The work shift for the tower controllers in small airport towers is normally $6-8 \mathrm{~h}$, with some brief breaks that arise when there is no traffic and the assistant monitors the situation.

The airport for the large tower used in this study had approximately 240,000 movements in 2017. The ATCOs work in groups of two to eight people (depending on the time of the day) consisting of air traffic controllers, air traffic control assistants and a team leader. The ATCOs have their own set of ATC tools. ATCOs work at different positions, such as landing, arrivals or ground service, in different shifts and at different times of day. The work shift for tower controllers is normally 20-60 min of work followed by a 20-min break, which is repeated for approximately $8 \mathrm{~h}$ in total. However, this might differ for night-time shifts.

The work in a tower control differs from en-route control and TMA control since the ATCOs in the tower have visual contact and can see the aircraft and vehicles they are controlling through the window, whereas the en-route 
controllers and TMA controllers use radar as the primary source of information.

\subsection{Teamwork theory}

Teamwork between people can occur at different levels, for example at an individual level (two people), at a group level (three or more people), or at an organisational level (where the teamwork extends over different hierarchic levels). A commonly used definition of a team is: "A distinguishable set of two or more people who interact dynamically, interdependently, and adaptively toward a common and valued goal/ object/mission, who have each been assigned specific roles or functions to perform, and who have a limited life-span of membership" (Salas et al. 1992, p. 4).

Teamwork is a common way to organise work in many different types of operation, and many theories for how efficient teamwork should be pursued have been proposed. From the vast and fragmented literature of teamwork, Salas et al. (2005) compiled an overview of empirically supported claims. They proposed a model for effective teamwork, which they called the "Big Five" model, based on five core components and three supporting mechanisms. The core factors in the "Big Five" model are: team leadership, mutual performance monitoring, backup behaviour, adaptability and team orientation. The three coordinating mechanisms, which Salas et al. identified as necessary to support the five main factors, are shared mental models, mutual trust, and closed-loop communication. Table 1 presents the five main factors and three coordinating mechanisms that constitute the "Big Five" model of effective teamwork, with the definitions and behavioural markers given by Salas et al. "Behavioural markers" are descriptions and examples of how each factor may manifest itself during teamwork.

The $\mathrm{T}^{2} \mathrm{EAM}$ model presented by Kontogiannis and Malakis (2017) is similar to the one presented by Salas et al. (2005). The model uses teamwork functions (cognitive functions) such as: team orientation, coordination, information exchange or communication, error management and change management. This model contains behavioural markers as well to describe the teamwork functions. In addition, the $\mathrm{T}^{2} \mathrm{EAM}$ model lists cognitive strategies used for the cognitive functions (teamwork functions).

Even though the "Big Five" model and the T2EAM model are similar in many ways, the latter contains error management which the "Big Five" model lacks. However, both models cover communication, adaptability, shared understanding, information sharing and feedback. There are also teamwork models regarding behavioural markers of teamwork breakdown (Wilson et al. 2007) and how to measure and improve teamwork (Brock et al. 2017; Leonard et al. 2004).
Salas et al. (2005) claim that the "Big Five" model contains factors that are necessary for teamwork to be effective regardless of the type of team and domain. However, they accept that it is necessary to investigate each domain, since circumstances such as team task and the location of the work affect how the factors manifest. Since our study investigate teamwork in different ATC environments with different types of teams (ATC for en-route control, terminal area control, tower control at a small airport, and tower control at a large airport), we chose the "Big Five" model as the foundation for our study.

The "Big Five" model uncovers the "black box" of teamwork processes and looks inside, rather than focusing on input (information given to the team) and output (the actions taken by the team), as many other teamwork models do. [See, for example, the classic model proposed by McGrath (1964).] The "Big Five" model offers a holistic framework, and aims to cover the many different essential aspects of teamwork.

The article by Salas et al. (2005) regarding the "Big Five" model for effective teamwork has been widely cited, but attempts to apply the model to different domains have been few. The model was used as a basis for a large longitudinal study of army peace-keeping teams (Duel 2010): it has been applied in a learning environment (Kay et al. 2006b), and it has been used for project teams (van Roosmalen 2012). In addition, a study similar to ours used the "Big Five" model in interviews with fighter pilots about their experiences of teamwork (Ohlander et al. 2016a). Since the model has been successfully applied to these other domains, we believe it will contribute to the aim of the study.

\section{Methods}

This study is based on interviews with 16 ATCOs in four air traffic control environments: en-route control, terminal area control, tower control for a small airport, and tower control for a large airport in Sweden. The interviews were analysed using the "Big Five" model (Salas et al. 2005) as a basis, including further development of the model by Ohlander et al. (2016b).

The aim of the interviews was to obtain an understanding of how the ATCOs perceive teamwork in their everyday work, and how they rank the five core factors and the three coordinating mechanisms in importance. The participants were asked to speak freely about the eight factors, one factor at a time, and give examples of situations or events in which the factor had been experienced, both regarded regular situations but also if they could give any examples of specific occurrences. The participants also indentified the 5, out of 23, behavioural markers (from the "Big Five" model, see 


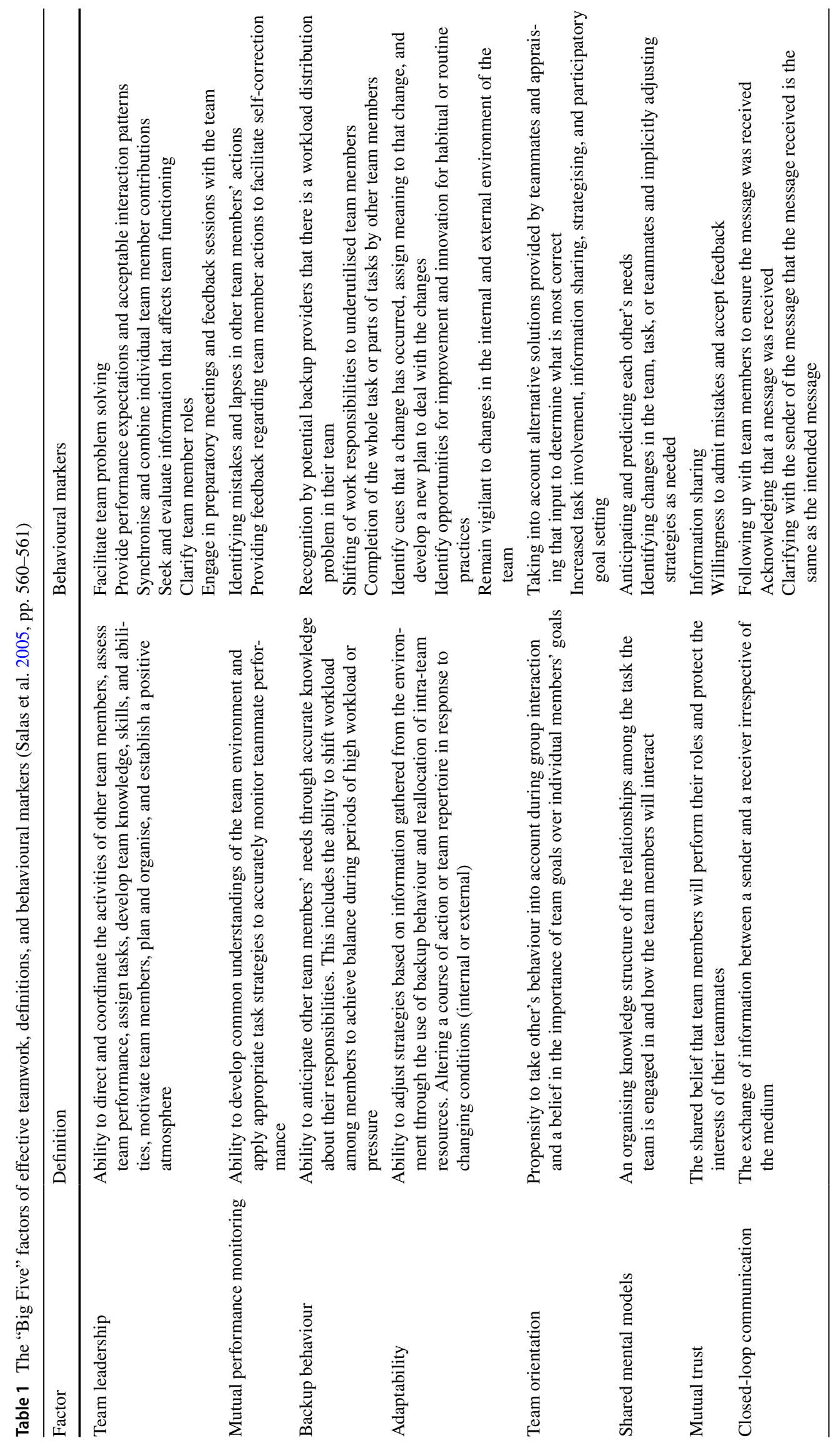


Sect. 2.2) that they considered to be the most important for teamwork.

The five core factors and the three coordinating mechanisms were presented as eight factors to the participants, since all eight factors are needed for teamwork (Salas et al. (2005). This presentation prevented external influences playing a role when the participants rated the importance of the factors.

We interviewed 16 ATCOs working in Sweden (13 male, 3 female) from 4 air traffic control environments: 4 en-route controllers (participants ENR1-4), 4 terminal area controllers (participants TMA1-4), 4 tower controllers at a small airport (participants TWRS1-4), and 4 tower controllers at a large airport (participants TWRL1-4). The participants had a median age of 36 years, and a median duration of experience of working as an ATCO of 7.5 years.

The interviews were held at the workplaces of the ATCOs. They were conducted in Swedish, to ensure that the participants could speak freely without any language barriers. However, the English labels and definitions from the "Big Five" model were used to avoid misunderstandings or translation errors.

\subsection{Procedure}

The interviews were conducted in five steps. First, the purposes of the interview and the study were explained to the participant. The participant signed a consent form confirming that he or she had been informed of the purpose of the study, how the results were to be used, that the interview was going to be audio recorded, and that it was possible for him or her to withdraw at any time without needing to give a reason. In addition, each participant completed a questionnaire with information about age and experience. Second, the participant described briefly his or her work, including such information as the sector or position held, and then described the perception of teamwork in ATC, especially with respect to their own work. The participants described their views on teamwork in their own words. Third, the participant was introduced to the "Big Five" model. The eight factors, written on separate paper slips, were presented and explained one-by-one. The participant gave examples of situations in which the factors had been experienced, both regarded regular situations and of specific occurrences. When the participant had explained his or her view on all factors, the participant was asked to rank the factors of their importance for teamwork in their work domain, starting with the most important factor, by placing the paper slips on the table. The participant was asked to explain and justify the ranking. Fourth, the behavioural markers were presented and explained to the participant. The participant read the descriptions of all the behavioural markers on his or her own, given in a randomised order on a paper sheet, then marked the five behavioural markers that the participant found most relevant for teamwork. Five behavioural markers were chosen so the participant had to narrow down what he/she believed were of most importance. The participant's ranking of the teamwork factors with the chosen explanations of the factors (the behavioural markers) were compared to see if the participant would pick the same factors as most important when they read the behavioural markers. Finally, the participant was asked if there was anything else to describe or discuss regarding teamwork. The length of each interview was 40-60 min.

\subsection{Analysis method}

The audio files recorded during the interviews were transcribed with what the participant had said during the interviews, with timestamps.

The text files were imported into the Dedoose software package for categorization of the "Big Five" factors and coding of the text. Ten codes were used to categorise the material in the interviews: one code for each teamwork factor (five core components and three supporting mechanisms), one code for an explanation of teamwork by the participant which the participants provided in the beginning of the interview, and one code for comments about ATC functions and tools that the participants mentioned when they gave examples of situations with the factors. The coding was performed to sort all the comments and divide them into categories. All the comments by the participants were divided into these ten codes. After the coding, all comments for each air traffic control environment were compiled into Excel for further analysis. The comments within each code where categorised into the participant stating the comment and the ATC domain the participant were working at.

The ranking of the teamwork factors and the behavioural markers done by the participants were compiled and calculated for each ATC domain, to meet the purpose of the study.

After compiling the results from the ranking of the teamwork factors and the behavioural markers, the results were compared with the comments for each teamwork factor. Comments used in the paper were translated into English.

Comparisons within groups (en-route, TMA, TWR small and TWR large) were made with Kendall's coefficient of concordance $(W)$ (Kendall and Smith 1939), which is a well-established teamwork analysis method (Berggren 2016; Brannick et al. 1997; Siassakos et al. 2011). Kendall's $W$ is a more robust statistical test than, for example, Spearman's rank correlation coefficient (Croux and Dehon 2010). Kendall's $W$ ranges from 0 to 1 . Hence, if all participants in a group pick the same order of all options, Kendall's $W$ will be 1 . A value above 0.50 indicates that the members of a group ranked the factors in a similar way. Kendall's $W$ was calculated using a non-parametric test in SPSS. 


\section{Results and analysis}

The results have been broken down and reported for each of the four sub-groups of controllers: en-route, TMA, and the two kinds of towers (one small and one large airport). The results for the ranking of the teamwork factors are presented first, followed by a selection of the most significant behaviour markers. Detailed descriptions of each factor are then given.

\subsection{Ranking of teamwork factors}

Table 2 presents the ranking of the importance of teamwork factors from the "Big Five" model.

Kendall's coefficient of concordance was low $(W=0.29)$ for the total group, which shows that the different sub-groups ranked the factors differently. Mutual trust was ranked as the most important factor for all groups combined, while team leadership was ranked as the least important factor. The en-route group, the TMA group and the small airport tower group ranked team leadership as the least important factor, while the large airport tower placed it as number five. The en-route group was the most united in the perception of the teamwork factors with $W=0.76$. The small airport tower group was the least united, with $W=0.26$. To note, since the study is a descriptive one, containing only four ATCOs per ATC environment, the results from Kendall's $W$ should be used with caution.

All four participants of the en-route group ranked adaptability as the most important factor and team leadership as the least important. When selecting 5 of the 23 behaviour markers, the en-route group selected identify cues that a change has occurred, assign meaning to that change, and develop a new plan to deal with the change, which is behaviour that characterises adaptability (Salas et al. 2005). Hence, for the en-route group, the ranking of the most important factor and the behavioural markers selected were consistent.

The ATCOs in the TMA group ranked the teamwork factors differently from the ATCOs in the en-route group. They ranked mutual trust as most important, with shared mental models in second place. The TMA group ranked team leadership as least important, as the en-route group had done. The behavioural marker that the members of the TMA group selected most frequently was information sharing, which is a consequence of mutual trust (Salas et al. 2005). This is compatible with the members of this group most often ranking mutual trust as most important.

The members of the small airport tower control group ranked mutual trust as the most important factor, and team leadership as least important, as had the members of the TMA group. However, the participants in the TWR small group selected clarifying with the sender of the message that the message received is the same as the intended message as the most important behavioural marker, which is a characteristic of closed-loop communication. Hence, for the TWR small group, the most selected behavioural marker did not agree with the highest ranked factor.

The participants from the TWR large group ranked mutual trust as the most important factor, and mutual performance monitoring as the least important factor. The two most frequently selected behaviour markers for this group were "willingness to admit mistakes and accept feedback" and "information sharing", both of which are characteristics of mutual trust.

Table 2 Results of the ranking of the teamwork factors and Kendall's coefficient of concordance $(W)$ given for each sub-group of interviewed ATCOs. 1 is most important and 8 is least important

\begin{tabular}{|c|c|c|c|c|c|}
\hline Importance & En-route $(W=0.76)$ & TMA $(W=0.58)$ & TWR small $(W=0.26)$ & TWR large $(W=0.40)$ & All $(W=0.29)$ \\
\hline 1 & Adaptability & Mutual trust & Mutual trust & Mutual trust & Mutual trust \\
\hline 2 & Mutual trust & Shared mental models & Shared mental models & Team orientation & Adaptability \\
\hline 3 & Backup behaviour & Adaptability & $\begin{array}{l}\text { Closed-loop communi- } \\
\text { cation }\end{array}$ & $\begin{array}{l}\text { Closed-loop communi- } \\
\text { cation }\end{array}$ & Shared mental models \\
\hline 4 & $\begin{array}{l}\text { Closed-loop communi- } \\
\text { cation }\end{array}$ & Backup behaviour & Adaptability & Backup behaviour & $\begin{array}{l}\text { Closed-loop communi- } \\
\text { cation }\end{array}$ \\
\hline 5 & $\begin{array}{l}\text { Mutual performance } \\
\text { monitoring }\end{array}$ & $\begin{array}{l}\text { Mutual performance } \\
\text { monitoring }\end{array}$ & $\begin{array}{l}\text { Mutual performance } \\
\text { monitoring }\end{array}$ & Team leadership & Backup behaviour \\
\hline 6 & Shared mental models & $\begin{array}{l}\text { Closed-loop communi- } \\
\text { cation }\end{array}$ & Team orientation & Adaptability & Team orientation \\
\hline 7 & Team orientation & Team orientation & Backup behaviour & Shared mental models & $\begin{array}{l}\text { Mutual performance } \\
\text { monitoring }\end{array}$ \\
\hline 8 & Team leadership & Team leadership & Team leadership & $\begin{array}{l}\text { Mutual performance } \\
\text { monitoring }\end{array}$ & Team leadership \\
\hline
\end{tabular}




\subsection{Description of the teamwork factors}

In this section, the eight teamwork factors from the "Big Five" model are described in the context of each sub-group. Quotations, which are translations from Swedish, are given as illustrations.

\subsubsection{Team Leadership}

Team leadership was perceived in different ways in the different control environments. For en-route, TMA, and the small airport tower groups, team leadership was ranked as the least important factor, and the role of the leader was considered to be more one of support than one of leader. Since the ATCOs in these three groups have control over their sector or control zone, there seems to be no need for a team leader. However, team leadership is more important for the large airport tower group, and is ranked as the fifth most important factor.

Team leadership is not prominent in the en-route group. The role of the team leader is considered to be more one of support than one of leader. The team leader is to make sure that everything works outside of the sectors by managing phone calls, coordinating with other sectors and the military, keeping track of the traffic flow, weather, runway combinations at airports, and so on. ENR4 said: "The leadership of the working group is not very noticeable; the group manages itself in many ways". However, the executive, E, is responsible and has a mandate over the sector and is a leader in relation to the planner, P. ENR2 said: " $E$ is responsible for the sector, so E decides over $P$ how the traffic to the sector should be handled".

The ATCOs working in the TMA consider the team leader to be the leader of the group. However, the role is again considered to be more one of supporting the team members than leading them. The ATCOs in the TMA group, similarly to those in the en-route control group, are in charge of their own sectors and can decide, for example, whether they need to open another sector because of high traffic load. TMA6 said: "In the OP room (operation room), there is not much team leadership. We have the team leader in there who can support and help if necessary. However, it is really more of a supporting role, not so much manager".

In the small airport tower group, in which an ATCO and an assistant work together, the ATCO is the leader and has a mandate and responsibility for the tower. However, this might change, depending on the task. For example, if something concerns the ground personnel, the assistant takes a leadership role. "Team leadership, well, we are a team but basically an equal team since we strive for the same goal. Yes, there is a team leader who plans the air traffic, but when there is snow clearing, the assistant becomes the main operator. So it is more about what the focus is at the time. Is our focus to get the runway in shape or to land aircraft? It varies depending on task and time of year and so on." (TWRS4).

In the large airport tower group, team leadership was given more importance by the participants, with comments such as: "It (leadership) is a very important role. The team leader takes phone calls and coordinates everything; he or she is the spider in the web. Controllers and assistants work for a while, then they are on break and perhaps leave the tower. The team leader is there all the time and has an overview of the entire day." (TWRL4). The participants stated that the task of the team leader is to support the ATCOs: "Not in decisions regarding controlling aircraft and telling them when to turn and things like that. But other, strategic decisions. Shall we change runway? Now we have a tailwind. What's going to happen to the wind later? Is it only for an hour, well, then it's no use." (TWRL1). When the team leader is not in the tower, one of the tower control positions is given the mandate instead. This means that there is always one person who is designated leader of the team. TWRL1 said: "There is always someone in the team who can say 'Now we will do like this, if it's not ideal, then we need to take a new decision later.".

\subsubsection{Mutual performance monitoring}

Mutual performance monitoring was ranked as a teamwork factor of intermediate importance, at position number five for three of the groups. Only the large airport tower group gave it another ranking, in this case, the least important factor.

During en-route control, E and P work side-by-side and can see what the other person is doing. The two operators work not only in a person-to-person manner, but can also look at each other's screens. Some of the participants claimed to be able to detect stress signals and indications of high workload from their partner, either by body language or by the manner in which the person controls the traffic. One example that indicates stress, it was claimed, is that an operator allows aircraft to level off and remain at different flight levels, instead of instructing them to complete climbing in one operation. E and $\mathrm{P}$ can see each other's screens and this makes it relatively easy for each of them to determine and remain aware of what the other is doing. However, the ability of operators, both E and P, to keep track of the other person differs. Participant ENR2 said: "When the workload for $E$ is low, it is easy to notice that $P$ is maxed out. But if you as $E$ are overwhelmed with work, it is difficult to judge P's workload". Coordination with adjacent sectors is, furthermore, more complicated, since the operators are not working in the same area. Coordination is carried out by telephone and in a rather more formal manner. Participant ENR3 said: "You can look into the TMA, how much grey (jargon for the number of aircraft seen on the radar screen) is it in there? Then I don't 
call them and ask if I can let the aircraft enter with high speed because I can figure out it will be rejected'.

Since E and P can see each other's screens, the mutual performance monitoring between $\mathrm{E}$ and $\mathrm{P}$ is perceived as strong. The same is true for the TMA group, even though the operators here cannot see each other's screens. (This is not necessary because of each one has an own sector.) The operators in this case hear other team members, and assess traffic flow to determine the nature of the situation.

When traffic is low, people chat more with each other and they have time to look around and check the workload for the others in the room. Participant TMA4 stated: "If you don't hear anyone talk, you know there is much to do, otherwise people chat with each other. But when it is quiet and everyone is focused, you know there is a lot to do". In addition, they can determine the magnitude of the workload by noticing how much the shift leader is on the phone (the more phone calls, the more there is to do). The controllers in TMA also notice the way in which their colleagues handle traffic, which provides clues about the level of workload: "If I notice that my arrival director ends up with long approaches, I slow down my traffic, make them turn to adjust to the pace" (TMA3).

The ATCOs working in the TMA environment also carry out mutual performance monitoring with operators in adjacent sectors, to a lesser extent than within the TMA. If an ATCO in the TMA calls an ATCO in an adjacent sector and that person does not answer immediately, they assume the workload is high for that sector. Participant TMA4 commented on coordination with adjacent sectors: "When we coordinate within TMA, we can just shout to each other, 'Yes, I am getting close there', the dialogue gets more intense, but we work for the same airport and have the same goals. However, when we coordinate with ACC (area control center, i.e. an en-route controller), we have to call them and ask, 'How do you like this?' We don't know, we don't see their traffic situation. So that is a bigger project".

In a small airport tower, the ATCO and the air traffic control assistant have a good view of each other's work situation since they work side-by-side in the tower. This makes it easy to monitor each other: "You listen with one ear all the time to what the other person is doing, checking that everything is correctly done and all tasks performed" (TWRS1). There are also clues that can be used to judge the other sector's (TMA) workload: “...someone is on the frequency, and then I know they are busy with something, and if my issue isn't urgent, well maybe I don't have to press the button just then." (TWRS4).

In both types of tower, mutual performance monitoring is strong because the ATCOs sit close to each other and can see and hear how the other team members are working. The ATCOs in a large airport tower do not sit as close to each other as the operators in a small airport tower, but they are still aware of the traffic situation: "I think everyone is perceptive and very aware of the amount of traffic. Whether there is a lot going on at the moment or soon will $b e$ " (TWRL4). Since all ATCOs in the large airport tower are in the same room, they can hear each other talking: "You are always listening, even when you do your own thing. One ear is open to hearing what's going on" (TWRL1). "Everyone in the tower has big ears and hear everything that's happening. You pick up if someone gets a lot to do" (TWRL2).

The four control environments achieve mutual performance monitoring in a similar manner-by judging the level of the sound in the control room or tower and the activities on the radio frequency (on which the communication with the pilots takes place). Mutual performance monitoring in the team makes the team more aware of situations that arise, the traffic flow, and the workload of other team members. This enables them to predict to some extent upcoming events, and back each other up in abnormal situations or when needed.

\subsubsection{Backup behaviour}

Backup behaviour was given low importance by those who worked in the small airport tower, while it was among the four most important factors for the other groups. However, this behaviour occurs in all the control environments, and the participants stated that they try to help each other in the best way possible. This is only possible, however, when the traffic and the situation allow. In all of the ATC environments except the small airport tower, an example of backup behaviour is to call on one more person when the workload increases, which is an established method for support and help. In situations with a heavy workload, an additional person such as the team leader can come and stand behind an ATCO to observe and provide support. Several ATCOs found it helpful to have an extra pair of eyes, and experienced this as a relief. They did not feel that the person was watching for mistakes. Participant TMA4 said: "You can call for more people when needed, but even if you don't request backup, perhaps someone on his/her way out notices, 'Yes, I will stay here for a while and watch you'. Because perhaps there is too much going on to be able to hand over to someone else". In a small airport tower, in contrast, there is only one other person present: the air traffic control assistant. Indeed, during night shifts, the ATCO is in the tower alone and no one is available to provide this backup behaviour.

In en-route control, backup behaviour between $\mathrm{E}$ and $\mathrm{P}$ occurs as long as the workload allows. P monitors the traffic and tries to maintain an awareness of both the overall situation and the situation in and around the sector. However, when $\mathrm{P}$ has much to do, there is not much time available to watch the traffic that $\mathrm{E}$ is handling, and extra monitoring cannot be carried out. E can answer phone calls if $\mathrm{P}$ has a 
lot to do, but P is not allowed to carry out E's tasks, since E is responsible for the sector. Participant ENR1 commented on this difficulty in workload distribution: " $P$ can't take over that many of E's tasks. But when there are too many calls for $P$, E can also answer or make calls".

Moreover, changes in workload can be difficult to predict, as ENR4 stated: "Many times, when there is a lot to do, it may sound crazy, but you don't know it until you are in it. It increases slowly, you get more and more to do, and then suddenly, it's just too much". Since the goal of the work in ATC is to achieve flight safety, everyone is aware of the necessity to help each other: "If something happens, then you are not allowed to work more that day. Then everyone else must put in an extra effort because fewer are left" (TMA4). It is sometimes necessary to provide backup for adjacent sectors, as expressed by participant ENR3: "An aircraft is climbing in my sector and will descend in the next. Then I might ask them if I should keep controlling it because I can see they have a lot in there".

Regarding backup behaviour in the TMA, TMA3 said: "I think we help each other in stages. Less during take-off, because take-offs are easier, the aircraft start out close to each other and spread out. Landings are the opposite; aircraft begin far apart and then they get closer to each other".

In small airport towers, the ATCO can answer the phone for the assistant if he or she is already talking on another line. However, the assistant is not allowed to manage airborne traffic, and thus cannot take tasks for the ATCO: "If there is a call on the flight radio, and it is an aircraft, then it is the air traffic controller's job. Because he/she is responsible and has the mental picture of the situation" (TWRS1). TWRL1 from a large airport tower said: "I think it works well, the support to each other during peaks. It happens quite often that the workload is uneven, especially for the ground positions."

Operators from small airport towers may give backup behaviour a low importance since the assistant is not allowed to perform all of the tasks carried out by an ATCO. In other words, backup behaviour is not considered to be an important factor in the small airport tower environment due to the strict task allocation.

\subsubsection{Adaptability}

ATCOs consider Adaptability to be a very important factor. It is ranked as the most important factor by the en-route group, and given a high rank by the TMA group and the small airport tower group. Those working in large airport towers gave it an intermediate degree of importance.

In the en-route environment, $\mathrm{P}$ adjusts to the way $\mathrm{E}$ wants to work, since the role of $\mathrm{P}$ is to deliver the traffic flow to E. The participants described how some Es want a more "active" process, while others are more "laid back". ENR1 said: "There is no time for discussion and arguing, we just do it".

Moreover, the operators must adapt to the work of adjacent sectors to ensure smooth handovers of aircraft. Communication and collaboration are more formal between sectors, while they are more dynamic, flexible and adaptable between E and P. "The collaboration between $E$ and $P$ is very dynamic. It is not at all the same dynamics over a sector border. Then, there are standard solutions. However, between $E$ and $P$, there is adaptation all the time. How does E work? What are the plans? How can I as $P$ adapt and support E in the way he/she wants to work?" (ENR2).

Adaptability is also required if the weather changes suddenly or unexpected events occur: "The conditions are constantly changing; you have to adapt to the day." (ENR1).

Participant TMA2 described how adaptation works in the TMA environment: "I would say that we adapt all the time. You look around, not only at your own stuff but the neighbour's as well, and since we are service-minded, we always look for some shortcut or some way of saving distance or speed up or do as they like in order to save fuel and time". TMA4 stated that adaptability must be learned: "The hardest for a student is to learn to be flexible. To only direct everything, descend and turn, that's pretty easy. However, when something happens; 'Wow, I've never seen this before! How do I solve this? I have no idea.".

Adaptability in the small airport tower is described by TWRS1 as: "When I work, I always have a basic plan in my head, to begin with. But it's very seldom it holds for eight hours, there is constant adaptation". The same participant continued: "Yes, it's fundamental in this job. We do it automatically, maybe we don't talk much about it but we adapt to the weather, the traffic, and so on. We do it a lot, I'm sure you have heard it before. It's on and off all the time".

TWRL2 from the large airport tower environment said: "If I know my colleague is busy in one position, I can adjust my work. I can adjust how I deliver traffic, or I can take over someone else's area. Or offload by opening a new position, I guess that's adaptability". TWRL2 continued about abnormal situations: "There is always a plan B, that's necessary. It's people in the cockpit and things may break, equipment can fail both on our side and on their side, so there is always a plan B. If something happens, we need a backup. During take-off you always have to be prepared for the worst to happen, an engine can fail, and of course, it will be the engine that will make it necessary to turn towards incoming traffic".

\subsubsection{Team orientation}

The factor team orientation was ranked with lowest importance by the en-route, TMA, and small airport tower groups, while the large airport tower group ranked it in second place. This reflects that larger groups of people who cooperate 
closely are present in large airport towers, while pairs of people cooperate in the en-route and small airport tower environments.

Team orientation is essential in ATC. The ATCOs work closely together and consider how their decisions and actions affect the next sector and the next ATCO. Working solo is not an option for ATCOs-participant ENR4 said: "You cannot do anything egoistic, it will affect everyone.", while participant ENR3 said: "No lone wolves here. It doesn't work in this environment".

Even though the ATCOs did not always rank this factor highly, they often commented how obvious and self-evident this factor is. They are of the opinion the work cannot be done if a team orientation is lacking, if there are only solo players and no team spirit. The participants pointed out that solo players do not belong in ATC and people are dismissed from the initial training if they cannot work in a team. As participant TWRL2 stated: "To be a team player is very important. As early as during recruitment, this is stressed. The lone wolves are not welcome, good at their part, but no collaboration. Those are sorted out as quickly as possible, they don't fit in".

The ATCOs consider how the traffic will affect the next sector. Moreover, they find it easy to feel that they are a part of a larger organisation: as participant TMA3 said: "I think it is quite easy for us to see the big picture and work towards the team goals since we are all a part of it. We don't land aircraft by ourselves, we don't take them from Gatwick to Arlanda, we don't follow them the whole journey, just a small part of it. You manage either the take-off, the middle part, or the landing. I think it's easy to get a feel for the global situation, and you expect a good delivery from your precursor - that aircraft enter with good bearing, good speed and not on top of each other".

Problems have arisen on some occasions when single players have wanted aircraft to take flight shortcuts to save the airlines money. Such shortcuts may affect the ATCO in the next sector in a negative way, highlighted by participant TMA4: "I would say we have had some problems with this. Everybody is very keen on keeping the pilots happy and helping the airlines to save money by travelling the shortest distance with continuous descent and high speed, and it may work for me but not in the next sector".

The ATCOs do not work solo, but work together towards common goals. It is not only in the tower that they experience this identity, but also throughout the organisation. Participant TWRS4 commented: "The whole business is team-oriented; it takes teamwork to direct the traffic from point $A$ to $B$. The goal is for everyone to strive for perfection and flexibility for all. You try not to give your colleague a higher workload if it can be avoided". Another participant (TWRS2) said: "It's not about one air traffic controller who does his thing, but about us in the tower doing our thing".

\subsubsection{Shared mental models}

The factor shared mental models was ranked as the third most important factor by all groups in combination. The TMA and the small airport tower groups ranked it as the second most important factor, while the en-route group ranked it as sixth most important and the large airport tower group as seventh.

Shared mental models is something unspoken between the team members, and it is important that the ATCOs have the same idea about how the aircraft should be routed through space. Different thinking is not acceptable, and a very smart idea from one person will not be accepted as long as the others do not share this way of thinking. "The mental models are very much based on basic separations (minimum distances between aircraft), that you have the same thinking, to start from a safe altitude. This is something common for all ATCOs over the whole world I think" (ENR2). Shared mental models are established during training and through experience, and the concept expresses the idea that the team members have the same ideas and expectations of how to work: "We have well-working routines for both emergencies and, for example, snow. Everybody knows what's expected and who is doing what. Everything is very scheduled. That's important" (TWRL2).

Rules determine how the operators handle the aircraft: “...and what's in our local manual, there it is stated what we must do. Maybe not so much how we do it, but what should be done" (TWRS1). Participant TMA2 referred to the training as one of the reasons for the strong shared mental model: "Well, I think it is based on common expectations. Basically, we have the same training, we work in the same air, and we have worked in the air for a long time and we have a way of doing things."

Shared mental models arise not only from the use of the same training and manuals: ATCOs prefer to work with someone they know: "Above all, there is not much time, so it's nice to work with someone you know thinks alike because you don't always have time to ask." (ENR4). The communication between the team members is also affected by well-established shared mental models: "For this problem, we do this, for that problem, we do that. Based on that, we can make quick decisions and very little communication is needed to say what I intend to do." (TMA2).

The mental models that are shared may differ between different constellations of workmates: "As a newcomer, it may be difficult to know that things are so habitual and not written down, and different ways in different situations. When there is snow clearing, things are this way, and when there is a different runway, it's that way. Once you get used to it you will understand the philosophy behind". (TMA3). Participant TWRS1 said: "It grows with time and learning, etc. When you are in training, you reach an acceptable level, 
which still is OK. And when you work with a newcomer, you know that the person knows the job thus far, but everyone else is on this level. Then I will have to assist with the last part, which means that we can't have shared mental models as much as I can with an experienced person. Still, it's not absent; it's there, but not all the way".

However, even though solo playing and different thinking are not acceptable among the ATCOs, slightly different ways of working are. Operators work with different colleagues on different shifts, and this means that they adjust and adapt to the other's way of working and to the team. Some participants said that it is the more experienced ATCOs whom the others follow, and that they adjust their behaviour and their work strategies to fit into the other team member's mental model.

\subsubsection{Mutual trust}

All groups ranked mutual trust highly. The en-route group ranked it as the second most important factor, while the other groups ranked it as the most important factor. This probably reflects the idea that all ATCOs are part of a bigger system. No ATCO "owns" the ATC service and guides the traffic alone. It is always a team effort, to which each person contributes. To keep safety at the highest possible level, the ATCOs must trust their colleagues also to do their part.

The trust between the ATCOs in the same sector, area, or tower is strong. They trust that the team members will do what they are supposed to, that they all handle the traffic safely, and that they try to make decisions that do not affect the others in a negative way (such as handing over traffic on the wrong flight level or during a conflict). When critical information is to be communicated, ATCOs will sometimes listen to the others to ensure the message has been received and that the orders are followed, as a way of maintaining trust and mutual performance monitoring. However, in nearly all situations, they trust each other completely. This is one of the most important teamwork factors within ATC, and ATCOs stated that they cannot work with each other if they doubt each other or if they need to doublecheck each other.

In en-route control, mutual trust between the $\mathrm{E}$ and $\mathrm{P}$ is perceived as very strong. It is also strong between ATCOs in different sectors within an area control centre, but not as strong as between the $\mathrm{E}$ and $\mathrm{P}$, since the ATCOs normally do not know who is working in the other sectors. Trust towards each other is necessary since there is no time or energy to doublecheck what the other team members are doing. Trust is something that builds up between the colleagues-from the day the student starts with an instructor in the control room until the day the ATCO gets checked (graduates): "Between $E$ and $P$, it's very strong. Between sectors inside the control room it is also strong. Not as strong because you don't have that knowledge about the individuals. As an E,
I am not aware of who is in the adjacent sector." (ENR2). ENR4 stated: "When you are new, you are treated like a child, he hasn't been here for long so we'll see if he does it right or what happens. After a while, they understand you have the same training and you have passed through it all".

The ATCOs in TMA control trust each other and this is very clear to them: "It exists, and it is important." (TMA2). In addition, they can always get help from one another when necessary, and they can rely on obtaining help from each other when there is a lot to do: "If I need help, I know I will get that help" (TMA3).

All ATCOs must demonstrate their trust during the regular training every year since this is necessary to prove that they can do a safe job. Trust is also built between the team members over the years, through their time as students, during shifts, and during training: "Students, who come from outside, they have to gain experience and trust from the others." (TMA1). With strong trust comes also honesty, and ATCOs who trust each other do not doublecheck each other's work: "I must be able to trust that others are doing their job, and they must be able to trust that I do mine, in that I don't have to check their traffic and they don't need to check mine. But, we have mutual awareness and help each other. If I do something that doesn't work for someone else, I trust that they will tell me." (TMA4).

Mutual trust is also strong between ATCOs working in a small airport tower. They do not doublecheck each other. However, they listen to each other, to be sure that the other team member is doing what he or she is supposed to do. "You don't sit there with eagle eyes: 'Do they really do that?' It's more you listen with one ear that things are done and if it's not done, you remind them. People do forget." (TWRS1). Without trust, the work would be more difficult, as TWRS4 stated: "You want to trust your colleague to do what he or she is supposed to and that the person is feeling safe working with me. That I do what I'm supposed to. To work with someone you feel maybe takes shortcuts or things get too tight, no that's not good". Work performance may also be affected by the team members' trust: "The level of air service achievement may rise when there are two ATCOs and one is actively helping the other." (TWRS3).

In a large airport tower, the team is normally bigger and, therefore, there are more people to trust. TWRL3 said: "I never doublecheck; I trust all my colleagues and that they do what they are supposed to, I know they will'. The same ATCO continued: "But I will question if I feel something seems to be odd, that's also important. I hope they do that to me also, or I know they do".

\subsubsection{Closed-loop communication}

ATCOs in three environments ranked closed-loop communication as having intermediate to high importance, 
the exception being the TMA group, which ranked it as number six.

ATC uses a standard phraseology in English, which includes clearances from the transmitter (ATCO), readbacks from the receiver (pilot or another ATCO), and confirmation from the transmitter (ATCO). The phraseology between the ATCO and the pilot is well-established. A standard phraseology has been established also between ATCOs, but this is not as clear as the phraseology used with pilots. When communicating with aircraft, the readback of messages is a requirement and self-evident. TWRS3 expressed this as: "Closed-loop is a prerequisite for everything". TWRS3 continued: "I don't even know if it should be included". Communication uses a short and precise phraseology to minimize the risk of misunderstanding, as ENR3 made clear: "We have never a lot of talk around, so it can't be misunderstood." TMA3 said: "Very pronounced in this job since we demand readback on all instructions. We are taught that the readback, that's what is important, not the order because that's when it is acknowledged. So no matter what I say, it is what is read back that is going to be executed."

However, communication between ATCOs is not always as clear as needed in any of the control environments. This is often brought up during training as an issue to improve: "This is something that keeps coming back at our checks (training), to be clear at coordination, use the entire callsign, read back. But whether or not it is regulated, I don't know." (ENR2).

Acknowledgements are often given by gesture, such as a thumbs-up, or by a short "Yes, OK" if the person is busy with something else at the same time. Acknowledgements can also be picked up indirectly by hearing that the order is given to an aircraft or the altitude can be seen on the radar screen: "We get their selected altitude, their indicated speed, Mach number, magnetic heading, descending velocity, ascending velocity. That's all we need." (ENR2). ENR2 continued: "If I am unable to hear him before I would have asked immediately, 'Confirm new altitude', but now I can wait 5 s to read what he has entered (into the digital system). We are not allowed to use this as an accurate source, but I can admit that it is done. This support is amazingly good, the best thing that happened to us ever. It saves us a lot of capacity.". Misunderstandings may occur due to a lack of stringent communication, which is another concern: "We talk about 'the SAS there', but there are actually plenty of SAS, and if someone is looking at another SAS, we have a problem. It has happened." (ENR2). However, the ATCOs sit closely together in the control room and can hear what the other team members are doing. ENR1 said: "We hear what the other one is doing so we get a kind of picture that he/she has understood or not".

\subsubsection{Summary of results}

Table 3 presents a summary of the results. The table presents the clearest results of how the teamwork factors are manifested in relation to the different ATC environments and why the teamwork factor is important in ATC.

\section{Discussion}

\subsection{Overall discussion}

Even though the "Big Five" model is intended to apply mainly to theoretical research, regarding team leadership, our results are compatible with the descriptions of the factors given by Salas et al. (2005). We see that team leadership can affect the team effectiveness by enabling team problem solving, through cognitive processes, coordination processes, and effects on the motivation and behaviour of the team, rather than handing down solutions. For example, in the en-route and TMA environments, team leadership is seen as less important than in the other environments, since the team leader has more of a support role than a leading role. Instead, E is the leader for the en-route sectors, since he or she has the mandate over the sector. In the TMA environment, where only one ATCO occupies each sector, this operator has the mandate over the sector, but collaborates with other ATCOs in the TMA. The role of the team leader in the TMA is again that of support more than leadership. In contrast, in a large airport tower, team leadership is seen as one of the most important factors, and the team leader has many responsibilities (such as handling phone calls, coordination, sharing information, etc.). The leader also has knowledge about the overall situation in the tower. If the team leader leaves the tower, an ATCO is temporarily given the role. In a small airport tower, where only one ATCO works with one air traffic control assistant, the leadership comes naturally to the ATCO since he or she is the one with a mandate over the control zone.

The "Big Five" model suggests that mutual performance monitoring becomes increasingly important in stressful situations. A study by Vanderhaegen (1999) showed that there might be communication overlaps in control rooms during stressful situations and suggests that there should be more technical support for the operators to share the work environment, which could increase mutual performance monitoring. In our study, the participants stated that mutual performance monitoring was frequently maintained and manifested in the way that the ATCOs see and feel the workload in the room and back each other up if needed. However, they also stated that mutual performance monitoring decreased during stressful situations. During such situations, they had sufficient time only to focus on their own tasks, and did not have 


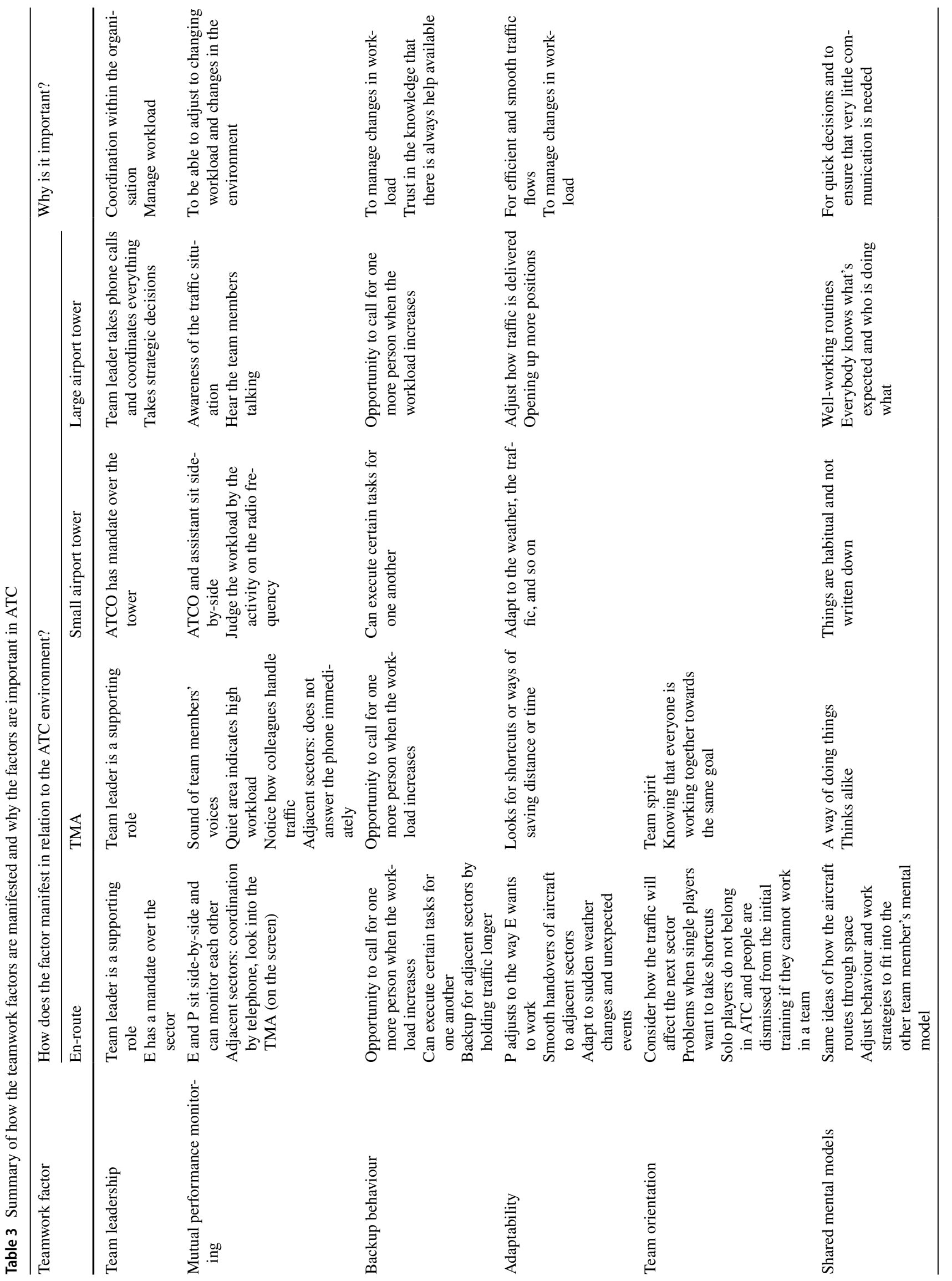




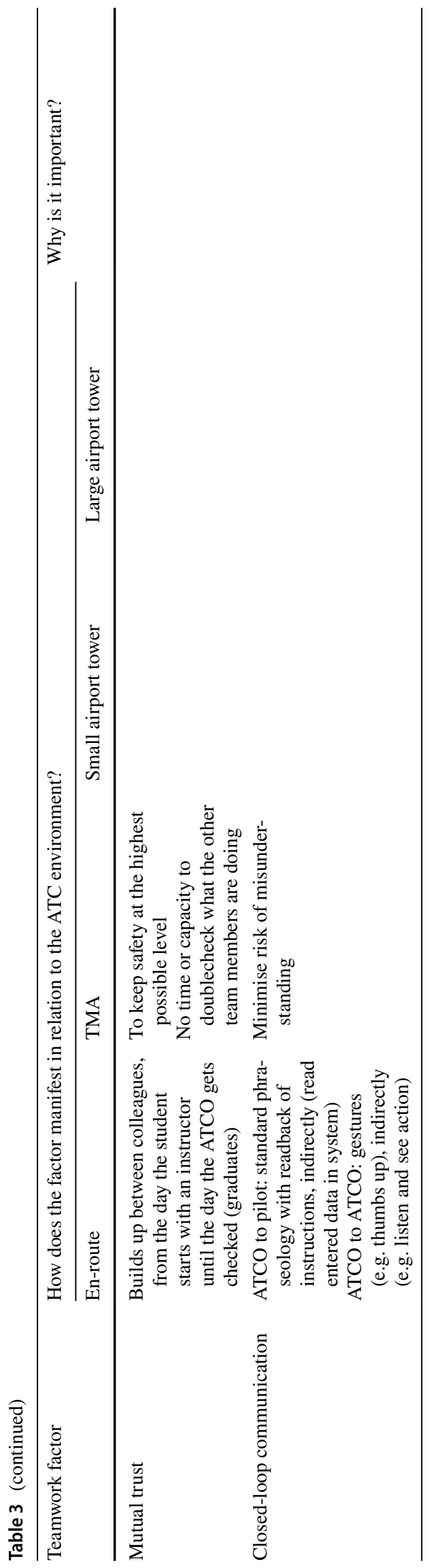

the time to listen to the sound in the control room or look around in the room in the same way as during calm situations. However, effective mutual performance monitoring can help to predict an increase in workload and, in this way improve the ability to prepare and adapt to such an increase. That could in turn lead to lower risks of communication overlaps (Vanderhaegen 1999).

The eight factors are highly correlated, and some factors might be interchangeable. In environments in which mutual performance monitoring was ranked with intermediate importance (en-route, TMA, and TWR small), team leadership was ranked with lowest importance. The opposite occurred for TWR large, where team leadership was ranked with intermediate importance and mutual performance monitoring with least. It is possible that these two factors are correlated and that self-synchronisation plays a role. When mutual performance monitoring has been established and is working well, team leadership is less important. The team is self-synchronised. Moreover, the strong leadership required by teams in large airport towers decreases the need for team members to keep track of each other: they rely more on the team leader. The same implications can be drawn regarding mutual trust and team leadership. When mutual trust was given a high importance, team leadership was given a low importance, and vice versa.

Backup behaviour contributes to an improved teamwork performance and is correlated with other factors. Backup behaviour ensures that a team can adapt to new situations, since the ATCOs help and support each other. This is of great importance in ATC in all four environments. Backup behaviour is related to shared mental models and mutual performance monitoring, and these factors can be used as a foundation when backup behaviour is needed. If shared mental models and mutual performance monitoring are strong, it is easier to predict when backup behaviour will be necessary and, therefore, operators will be able to prepare for it. Backup behaviour depends also on adaptability, and the ability to put aside some tasks to change behaviour and to help and support according to the situation.

Team orientation refers to taking others' behaviour into account and believing that team goals are more important than individual goals. It is the attitude of wanting to work in a group. Team orientation describes an attitude, or a state of mind, rather than behaviour or a state that can be achieved through experience. In work environments with selected and trained professionals and where the ability to work in a team is a prerequisite, as in ATC, team orientation can be taken for granted. This may be why three of four groups ranked it as one of the least important factors. People who do not exhibit team orientation are sorted out during the selection and training process.

Some ATCOs work in one way while others want to work in a slightly different way. This led several ATCOs to express 
the need to adapt to each other, and to make sure they share mental models. The "Big Five" model assumes that the factor shared mental models precedes adaptability. Thus, team members try to predict how other team members prefer to work, and adapt to that assumed way of working. It is clear that the teamwork factors are linked to each other, and affect each other differently in different domains and for different roles in the team. Some factors are interchangeable (mutual performance monitoring and team leadership), but these still affect the other factors, their relative importances, and how they are manifested.

Corver and Grote (2016) showed that ATCOs prefer to do what is "common sense" or "what is safe" in situations where they do not know the established procedures, and in situations in which established procedures are not applicable. This agrees with the findings of the present study, where the ATCOs emphasise that shared mental models are important. They know the procedures to be followed in known situations, and they share mental models that determine how to act when something unexpected happens.

Teamwork has already been studied extensively in aviation (Wilson et al. 2010) and ATC. Malakis and Kontogiannis (2008) and Malakis et al. (2010) focused mainly on abnormal situations and emergencies whereas Vanderhaegen (1999) focused on stressful situations. However, the present study has shown that it is not only during abnormal or stressful situations that teamwork is important. Teamwork is important also during routine work, since the team members must know what the other team members are doing, through mutual performance monitoring; and they must be able to adapt and communicate such that they can prepare for higher traffic flows and high workload situations. Good teamwork during regular work and normal situations can decrease the workload, since the team members know how the other team members are performing, and can support each other before or when a high workload arises.

\subsection{Design implications for teamwork in ATC}

The results presented here have implications for design of the ATC environment, the design of tools and functions, and the organisational structure. Table 3 shows that the design of all these aspects affects the teamwork factors of the "Big Five" model.

\subsection{Organisation}

ATCOs give several of the teamwork factors high importance. Therefore, the teamwork factors in the different ATC environments should be considered when designing ATC systems. Support for the teamwork factors is embedded in the organisation, sustained by either rules, regulations, or practices. Thus, for example, closed-loop communication is a requirement for coordination, not only between ATCOs and pilots but also between ATCOs. However, coordination between ATCOs is not always satisfactory, since the operators try to save time and minimise the workload associated with providing acknowledgements. They depend instead on the mutual trust between colleagues.

Team orientation and mutual trust are important criteria during recruitment and training. If these teamwork factors are not achieved during the training, the student is rejected from the programme. This is because such students will find it difficult later to adapt to the climate of team orientation and mutual trust in the workplace, and may not be able to get along with other team members. ATCOs believe that team orientation and mutual trust are two of the core factors for effective teamwork in ATC.

Backup behaviour is also embedded within the organisation and the digital systems used, since the ATCOs are allowed to take on each other's tasks (to some degree, depending on position). Within the TMA and the large airport tower environments, the ATCOs work in different sectors (TMA) or with different parts of the tower (arrivals, departures or ground service, depending on the shift and traffic flow), which means that backup behaviour can only occur between certain positions in the tower, even though mutual performance monitoring is strong in these environments.

Team leadership is achieved through the appointment of a formal leader (the team leader or a designated ATCO who has a mandate over the sector). The role of the leader, however, depends on whether the situation requires leadership or support.

The shared mental models factor is also developed and supported by regulations and practices. There is, however, considerable freedom in how the traffic can be routed, and some ATCOs invested effort in "reading" or interpreting their colleagues to adapt to their way of working. This should be investigated in more detail, and considered when designing ATC systems.

\subsection{Environment}

Closed-loop communication and mutual performance monitoring are affected by the design of the working environment, since the ability of ATCOs to see and hear the other team members depends on the seating arrangement in the control room. The ability to judge the workload in the sectors around them is also affected by the seating arrangement.

In en-route control, E and P work closely together and monitor each other. Thus, the design should be based on these two operators sitting together, working within the same sector, and having the same information on their screens.

In small airport towers, the ATCOs also work closely together and several design parameters may make it easy 
for the ATCO and the air traffic control assistant to maintain closed-loop communication and mutual performance monitoring, which leads to increased backup behaviour and adaptability. These design parameters include the size and layout of the tower, the ability to share radar screens, the availability of the same flight-strip progress-board, etc.

\subsection{Tools}

The tools that ATCOs use can support teamwork factors. For example, the shared information on the screens and the voice communication system allow for higher levels of mutual performance monitoring and adaptability. Sharing information through the system allows the ATCOs to maintain mutual performance monitoring regarding the traffic situation without having to look up from the screens.

In en-route control, the design of the digital system used by the ATCOs allows E and P to work closely together and to keep track and monitor each other, since the system gives them the same information on their screens. The design of the system can also provide enhanced closed-loop communication, or implicit communication, since the system makes it unnecessary always to use verbal communication. In addition to the radio communication, some communication can be transmitted through the system (by, for example, datalink to pilots), which can lead to a lower workload. The ATCOs do not need to talk to the pilots and team members at all times. Moreover, the design of the system may also facilitate closed-loop communication by allowing ATCOs to look at, for example, the radar screens and determine whether a message has been received.

The capabilities for adaptability and backup behaviour can also be facilitated by the design of the digital system, if this displays changes in the intensity and routing of the traffic. Prediction of changes in the traffic flow may also increase the ability to plan, and in this way respond to changes more effectively. Change of runway, for example, must currently be coordinated verbally with the team leader. This means that important information is communicated verbally with the team leader, in addition to verbal closedloop communication with pilots, ATCOs in other sectors and other team members. This could be improved by a different system design in which, for example, new runway combinations are displayed on the screens of the ATCOs. Such a change would also enhance mutual performance monitoring.

\section{Conclusions}

We have confirmed that teamwork is important in ATC during routine operations, and shown for how teamwork is differently manifested in different ATC environments. Some teamwork factors are more important in some ATC environments than others, an important finding for designing future ATC systems. The "Big Five" model for effective teamwork was used as an entry point for the study, and allowed us to collect rich descriptions of how the ATCOs collaborate with colleagues in the four environments studied. We have also shown that all eight factors are considered to be relevant, and that teamwork manifests in different ways in different environments and when carrying out different tasks. The importance of each teamwork factor differs between environments. The main conclusions of this study are:

All the eight teamwork factors are manifested by ATCOs in the studied ATC environments. However, the importance of the teamwork factors differs between the ATC environments.

Teamwork in ATC is important during routine operations, during stressful work and during abnormal situations. Some teamwork factors are interchangeable in ATC (e.g. mutual performance monitoring and team leadership). The teamwork factors affect each other (e.g. shared mental models and adaptability, closed-loop communication and mutual trust).

Implicit communication is often used, and the amount of verbal closed-loop communication between the team members in ATC is limited.

Mutual trust is seen as the most important teamwork factor in all ATC environments, followed by adaptability and shared mental models. Team leadership is seen as the least important factor in three environments, the exception being large airport towers.

The design of the organisation, the environment, and tools affects how teamwork factors manifest themselves.

Acknowledgements The study presented here was funded by the Swedish Transport Administration, the LFV Air Navigation Services of Sweden, NFFP (National Aviation Research Programme, NFFP62013-01201), which is funded by VINNOVA (Swedish Governmental Agency for Innovation Systems), the Swedish Armed Forces and the Swedish Defence Materiel Administration. We gratefully acknowledge the contribution of air traffic controllers and participants from LFV.

Open Access This article is distributed under the terms of the Creative Commons Attribution 4.0 International License (http://creativeco mmons.org/licenses/by/4.0/), which permits unrestricted use, distribution, and reproduction in any medium, provided you give appropriate credit to the original author(s) and the source, provide a link to the Creative Commons license, and indicate if changes were made. 


\section{References}

Berggren P (2016) Assessing Shared Strategic Understanding. ( $\mathrm{PhD}$ Doctoral thesis, monograph), Linköping University, Linköping, Sweden. Available from EBSCOhost edsndl database

Brannick MT, Salas E, Prince CW (1997) Team performance assessment and measurement: theory, methods, and applications. Psychology Press, Mahwah

Brock SE, McAliney PJ, Ma CH, Sen A (2017) Toward more practical measurement of teamwork skills. J Workpl Learn 29(2):124-133

Cooke NJ, Kiekel PA, Salas E, Stout R, Bowers C, Cannon-Bowers J (2003) Measuring team knowledge: a window to the cognitive underpinnings of team performance. Group Dyn Theory Res Pract $7(3): 179$

Cooke NJ, Gorman JC, Myers CW, Duran JL (2013) Interactive team cognition. Cogn Sci 37(2):255-285

Corver S, Grote G (2016) Uncertainty management in enroute air traffic control: a field study exploring controller strategies and requirements for automation. Cogn Technol Work 18(3):541-565. https ://doi.org/10.1007/s10111-016-0373-3

Croux C, Dehon C (2010) Influence functions of the Spearman and Kendall correlation measures. Stat Methods Appl 19(4):497-515. https://doi.org/10.1007/s10260-010-0142-z

Derven M (2016) Four drivers to enhance global virtual teams. Ind Commercial Train 48(1):1-8

Duel J (2010) Teamwork in action: Military teams preparing for, and conducting Peace Support Operations. (PhD Doctoral thesis), Tilburg University, Haag, Netherlands. Available from EBSCOhost edsnar database

Gyles D, Bearman C (2017) Managing safety in the air traffic control terminal airspace. Cogn Technol Work 19(1):143-159. https://doi. org/10.1007/s10111-017-0403-9

Hall P (2005) Interprofessional teamwork: professional cultures as barriers. J Interprof Care 19(sup1):188-196

ICAO (2005) Doc 9328: manual of runway visual range observing and reporting practices. Retrieved from International Civil Aviation Organization:

Jones GR, George JM (1998) The experience and evolution of trust: implications for cooperation and teamwork. Acad Manag Rev 23(3):531-546

Kay J, Maisonneuve N, Yacef K, Reimann P (2006a) The big five and visualisations of team work activity. In: Paper presented at the 8 th international conference on intelligent tutoring systems, June 26-30, Jhongli, Taiwan

Kay J, Maisonneuve N, Yacef K, Reimann P (2006b) The big five and visualisations of team work activity. In: Paper presented at the 8th international conference on intelligent tutoring systems, ITS 2006. Jhongli, Taiwan

Kendall MG, Smith BB (1939) The problem of m rankings. Ann Math Stat 10(3):275-287

Kontogiannis T, Malakis S (2017) Cognitive engineering and safety organization in air traffic management

Leonard M, Graham S, Bonacum D (2004) The human factor: the critical importance of effective teamwork and communication in providing safe care. Qual Saf Health Care 13(suppl 1):i85-i90

Malakis S, Kontogiannis T (2008) Cognitive strategies in emergency and abnormal situations training: implications for resilience in air traffic control. In: Paper presented at the 3rd symposium on resilience engineering, October 28-30, Antibes-Juan-les-Pins, France

Malakis S, Kontogiannis T, Kirwan B (2010) Managing emergencies and abnormal situations in air traffic control (part II): teamwork strategies. Appl Ergon 41(4):628-635

Manser T (2009) Teamwork and patient safety in dynamic domains of healthcare: a review of the literature. Acta Anaesthesiol Scand 53(2):143-151

McGrath JE (1964) Social psychology: a brief introduction: Holt, Rinehart and Winston

Neville TJ, Salmon PM, Read GJ (2016) Towards a model for measuring teamwork in Australian Rules Football Officials. In: Paper presented at the human factors and ergonomics society annual meeting, Los Angeles, CA

Ohlander U, Alfredson J, Riveiro M, Falkman G (2016a) Elements of team effectiveness: a qualitative study with pilots. In: Paper presented at the International Multi-Disciplinary Conference on Cognitive Methods in Situation Awareness and Decision Support (CogSIMA), 20-25 March, San Diego, CA

Ohlander U, Alfredson J, Riveiro M, Falkman G (2016b) A teamwork model for fighter pilots. In: Paper presented at the international conference on engineering psychology and cognitive ergonomics, July 17-22, Toronto, Canada

Salas E, Dickinson TL, Converse SA, Tannenbaum SI (1992) Toward an understanding of team performance and training. In: Swezey RW, Salas E (eds) Teams: their training and performance. Ablex, Norwood, pp 2-29

Salas E, Sims DE, Burke CS (2005) Is there a "big five" in teamwork? Small Group Res 36(5):555-599

Salas E, Cooke NJ, Rosen MA (2008) On teams, teamwork, and team performance: discoveries and developments. Hum Factors 50(3):540-547

Siassakos D, Fox R, Crofts JF, Hunt LP, Winter C, Draycott TJ (2011) The management of a simulated emergency: better teamwork, better performance. Resuscitation 82(2):203-206

van Roosmalen TM (2012) The development of a questionnaire on the subjective experience of teamwork, based on Salas, Sims and Burke's" the big five of teamwork" and Hackman's understanding of team effectiveness. (Master), The Norwegian University of Science and Technology, Trondheim, Norway

Vanderhaegen F (1999) Cooperative system organisation and task allocation: illustration of task allocation in air traffic control. Le Travail Humain 199:197-222

Wilson KA, Salas E, Priest HA, Andrews D (2007) Errors in the heat of battle: taking a closer look at shared cognition breakdowns through teamwork. Hum Factors 49(2):243-256

Wilson KA, Guthrie JW, Salas E, Howse WR (2010) Team process. Handbook of aviation human factors, 2nd edn. CRC Press, Boca Raton., pp 9-11

Publisher's Note Springer Nature remains neutral with regard to jurisdictional claims in published maps and institutional affiliations. 